\title{
Void Growth and Interaction in a Structural Aluminum Alloy: Experiments and Theory
}

\author{
Scott Gampert, Abu Bakar Siddique, Tariq A. Khraishi* \\ Mechanical Engineering Department, University of New Mexico, Albuquerque, USA \\ Email: ^khraishi@unm.edu
}

How to cite this paper: Gampert, S., Siddique, A.B. and Khraishi, T.A. (2021) Void Growth and Interaction in a Structural Aluminum Alloy: Experiments and Theory. Journal of Minerals and Materials Characterization and Engineering, 9, 14-37. https://doi.org/10.4236/jmmce.2021.91002

Received: November 9, 2020

Accepted: January 5, 2021

Published: January 8, 2021

Copyright $\odot 2021$ by author(s) and Scientific Research Publishing Inc. This work is licensed under the Creative Commons Attribution International License (CC BY 4.0).

http://creativecommons.org/licenses/by/4.0/

\begin{abstract}
The problem of void growth and interaction is of importance to understanding the mechanics of failure in metals exhibiting ductility. In this work, the growth and interaction of voids in 6061-T6 aluminum were studied experimentally. Specifically, holes of varying numbers and relative placement were investigated for their normalized area growth with applied displacement. Flat dog-bone specimens were carefully drilled in their gauge area with no (zero) holes, one hole, and two holes (arranged vertically or horizontally) for experimentation after polishing. The growth of holes, captured by video recordings, exhibited exponential behavior and was influenced greatly by the number and arrangement of holes with the horizontal voids growing the fastest and the vertical ones growing the slowest. Also, the ensuring deformation of the sample was studied using load-displacement curves, pictography and videography, SEM imaging and Atomic Force Microscopy (AFM). The methods revealed that although the major part failure is due to large crack formation, it was preceded by intense dislocation slip activity and the formation of micro cavities. Also, the AFM quantified the three-dimensional nature of crystal or grain deformation and how it is greatly influenced by distance and location from the hole. Lastly, theoretical understanding of hole growth was offered.
\end{abstract}

\section{Keywords}

Voids, Holes, Stress Concentration, Void Growth, Void Interaction

\section{Introduction}

The problem of void growth and interaction, or deformation mechanics in general/elasto-plastic nature of voids, has captured the interest of many researchers over time. The main reason is that void growth eventually results in component 
failure either during manufacturing (e.g. forming operations) or during operation. The failure is the result of the growth coalescing into larger voids that eventually accelerates the breakage of components or when a void bursts onto a component's surface. Most of these works focused on theory and or modeling (see, for example, [1]-[33]). The works by [4] and [34] represent good reviews covering the different aspects and proposed treatments for the problem of void growth.

There is less number of experimental investigations. The works of [35] [36], focused on evaluation of deformation-induced microstructural cavitation. Tait and Taplin [37] considered two neighboring drilled holes in a sheet of commercial Al-Mg alloy. The holes' centers were in a plane whose normal coincided with the tension axis. Forero and Koss [38] also considered a similar hole configuration but used spherical voids instead. Some studies focused on sheet specimens with a single void for investigating the growth behavior of such a hole. For studies with one hole, [39] focused on a superplastic copper alloy and [40] focused on a fine-grained $\mathrm{Pb}$-Sn alloy that presents superplastic properties at room temperature.

Other studies considered a sheet with either a random array of holes ([16] [41]) or an ordered array [41]. The first reference used $\mathrm{Pb}-\mathrm{Sn}$ eutectic alloy (as a superplastic material) and the second used four different materials (none of them were strain-rate sensitive). The main result of the first reference is that an increased void size caused faster specimen failure. The second reference showed that specimens with random arrays were less ductile than those with regular arrays.

Finally, the studies by [15] and [42] considered arrays of cylindrical and pre-machined holes that were aligned along the tensile axis. Kannan and Hamilton [42] used a eutectic Pb-Sn alloy and [15] used a modified AA5083 alloy. One of the main observations of these works is that ductility increases with an increase in the number of holes. The experimental study by [43], also on a eutectic tin-lead alloy, revealed an increase in ductility with the number of holes up to 10 holes and a decrease thereafter. This last reference also showed that for strain-rate sensitive materials, such as superplastic materials, it is possible to control the ductility of the holed specimen by appropriately choosing the applied strain rate. In the combined modeling-experimental study by [19], on eutectic $\mathrm{Sn}-\mathrm{Pb}$ alloy under uniaxial tensile loading, it was found that strain localization in the form of shear bands is significant in all holed specimens. It was also found that fracture tends to change from a ductile tearing mode to the shear banding mode as the number of holes increases. Yoshimasa et al. [44] did fatigue testing on precipitation-hardened Al-Mg-Si alloy (6061-T6) with a smooth surface and with a small artificial hole on the surface. The smooth specimens showed no distinct fatigue limit. Conversely, the holed specimens showed a clear fatigue limit, which had been generally deemed to be absent in non-ferrous alloys.

The current paper focuses on void growth and interaction, plus overall mechanical behavior, of a holed structural metal, namely 6061-T6 aluminum alloy. 
In addition, the paper focuses on multiple hole numbers and configurations. The paper also utilizes standard tension testing combined with videography, SEM and AFM techniques. Lastly, the paper provides, for the first time, theoretical understanding of the change in the stress concentration factor due to void interaction. All of the above makes this work rather unique in its approach. To summarize, the authors were interested in how does void growth and interaction differ or is similar to superplastic materials in the literature. Specifically, it aims to document experimentally the void areal growth versus applied stretching and give physical and theoretical explanation for it based on void interaction. Such experiments can serve as a basis to validate numerical models for void growth and interaction with embedded theoretical constitutive equations in them.

\section{Methods}

First off, two $6 \mathrm{ft}$ flat bars of $1 / 4$ inch thickness of certified 6061-T6 aluminum alloy were purchased. The bars were cut using an industrial-grade CNC mill (see Figure 1) into dog-bone specimens per the dimensions in Figure 2 and Figure 3. The 24 machined samples looked like the top-left part of Figure 4.

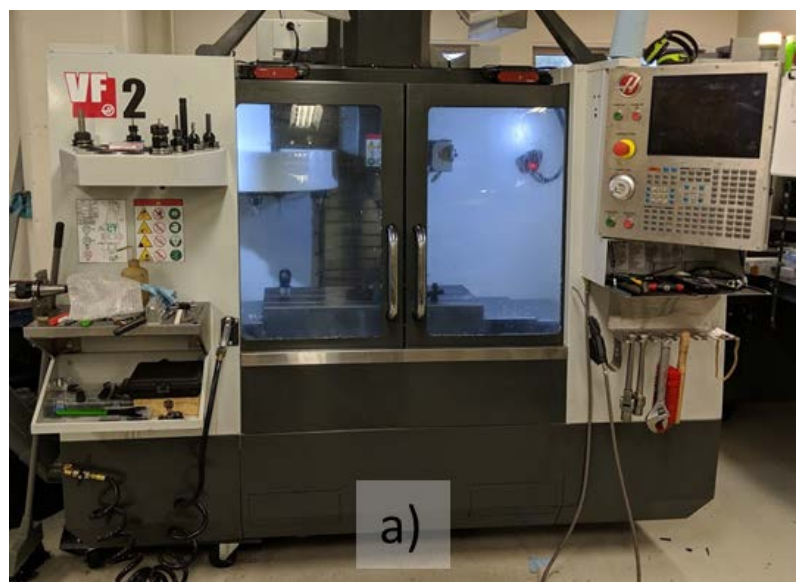

Figure 1. The CNC machine used in cutting the dog-bone specimens used in the tensile experiments.

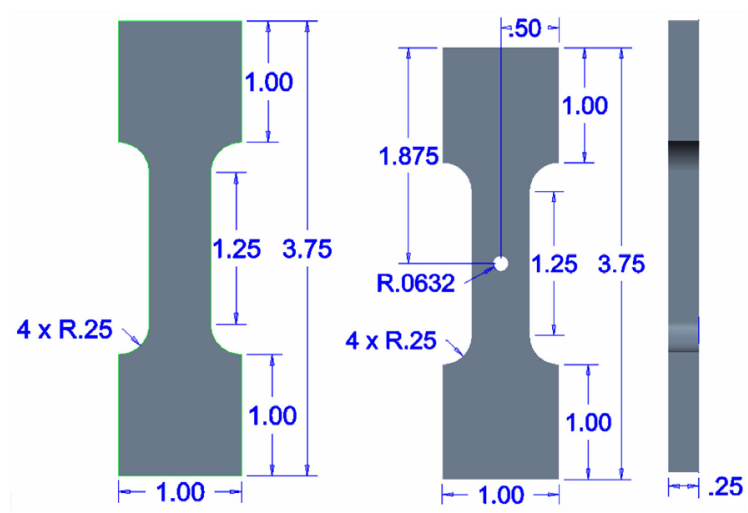

Figure 2. CAD drawings for specimens with no hole and one hole. All dimensions in inches. 


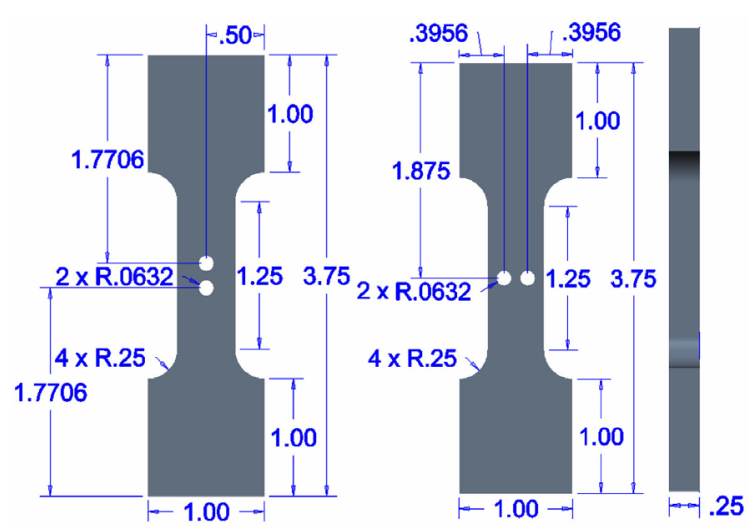

Figure 3. CAD drawings for specimens with 2 holes. All dimensions in inches.

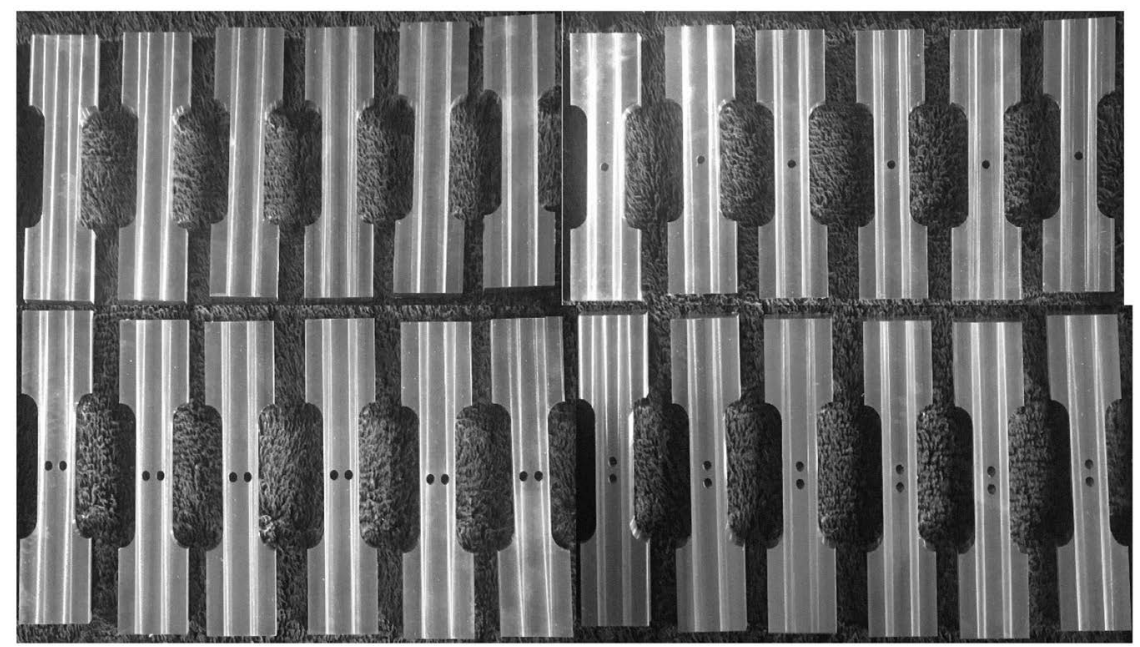

Figure 4. Unfinished dog-bone specimens. Specimens 1 - 6 of the "No Hole" configuration are on the top left corner. Specimens 1 - 6 of the "One Hole" configuration are on the top right corner. Specimens 1 - 6 of the "Two Horizontal Holes" configuration are on the bottom left. Specimens 1 - 6 of the "Two Vertical Holes" are on the bottom right corner.

Holes were introduced in 18 of the specimens. Each $1 / 8$ inch-diameter hole was created by drilling and reaming. Reaming produces smoother cut surfaces after drilling. Six specimens had a central hole, six specimens had two vertical holes and six specimens had horizontal holes (see Figure 4).

After the holes were created, all samples were then ready for fine grinding and polishing. In order to be able to handle such big specimens and apply even pressure on them during grinding and polishing, a special holder for the specimens had to be engineered. Figures 5-7 show side, bottom and locally zoomed-in images of the holder.

Using the holder, the specimens where grinded using 1000 grit sandpaper on a rotating disk for 3 minutes each and then rinsed off with water. The specimens were then polished on the rotating disk using nylon polishing cloth and 9-micron diamond paste plus diamond extender. The polished samples were then rinsed off and placed into a beaker of deionized water which was then placed in an ultrasonic cleaner for 3 minutes. This process was repeated for 3-micron diamond 


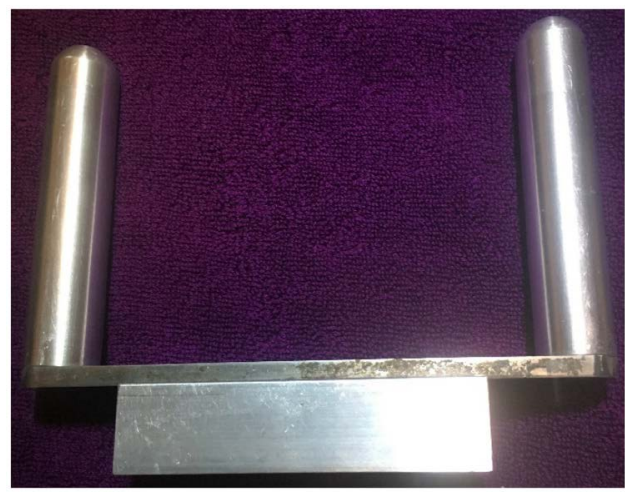

Figure 5. A picture of the specimen holder created to hold the specimens in place during grinding and polishing. There are two spread-out handles for the holder to assist in applying even pressure during grinding and polishing (to attain flat surfaces).

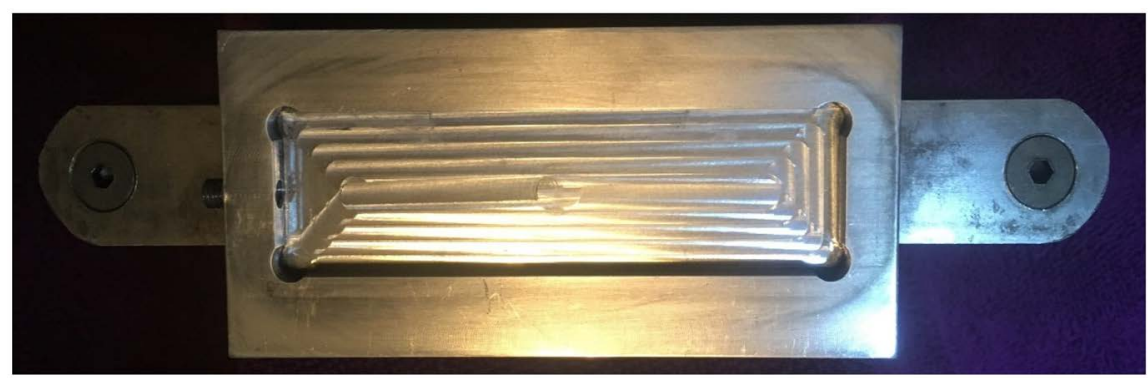

Figure 6. This is a bottom view of the holder showing where the specimen is held. The depth of the slot where the specimen is placed was slightly less than the specimen thickness.

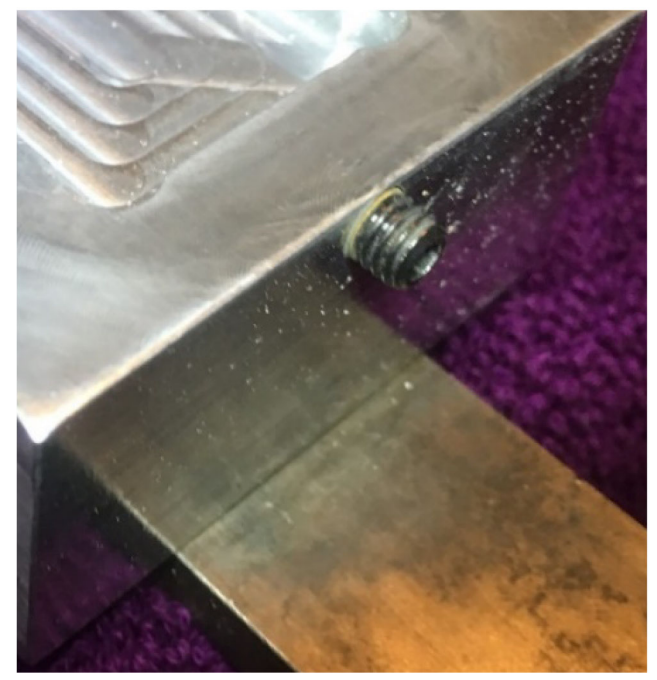

Figure 7. Shown here is a set screw on one end of the holder that is used to prevent any movement of the specimens during grinding and polishing.

paste and 1-micron diamond paste until the surface was mirror-like, as shown in Figure 8. The mirror-like surface was needed in order for the videography and pictography discerns the evolution of plastic deformation, through pictures and AFM, with loading in the specimen. 


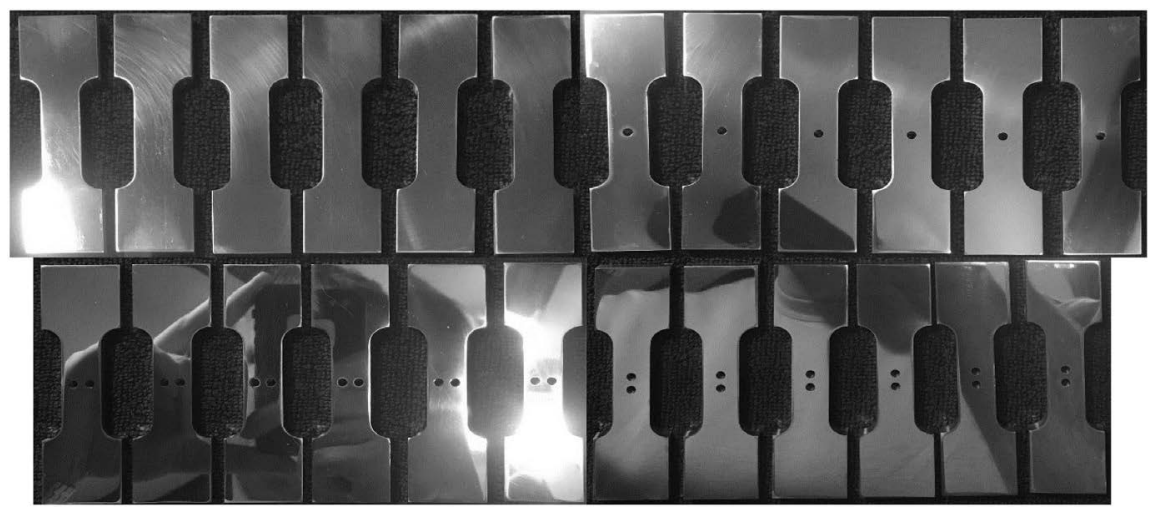

Figure 8. Polished specimens. Specimens 1 - 6 of the "No Hole" configuration are on the top left corner. Specimens 1 - 6 of the "One Hole" configuration are on the top right corner. Specimens $1-6$ of the "Two Horizontal Holes" configuration are on the bottom left. Specimens 1 - 6 of the "Two Vertical Holes" are on the bottom right corner.

Once the specimens were finished and ready for further experimentation, they were subjected to tensile loading at a pull-rate of 0.01 inch per minute in an Instron machine (with 20 kips load cell). This produced a load-displacement curve for each specimen. (In the RESULTS: The curves were very consistent, especially in their proportional limit and max load-bearing force, but not in their failure displacement which is common for tensile testing). The load-displacement curves were not converted into stress-strain curves (engineering or true) since, with the existence of the holes, there will be stress concentrations and a three-dimensional state of stress instead of a uniform uni-dimensional one like in standardized tensile testing.

Once the tension test is underway, a live video of the straining holes is recorded with a video camera to capture the changing area of the void(s). At the start of the test, the initial area (a circular area with a known initial radius) is captured and analyzed for its number of pixels in the software Image J. That provides the area per pixel. Then at different points in the test, the number of pixels was re-calculated to determine the current area of the void. This way, the normalized area (current area over initial area) growth with applied deformation can be determined and plotted.

Scanning Electron Microscopy (SEM) was also employed in this study instead of an optical microscope. When the specimen deformation occurs, rough surfaces are predicted to take place, especially near the holes, instead of the mirror-like polished ones due to dislocation slip activity. An optical microscope needs to be focused on a specific focal length in order to capture clear images/pictures. This is because an optical microscope does not have great "depth of field", also interchangeably called "depth of focus" compared to SEM. Hence, SEM should not have any problem capturing images of the deformed specimen surfaces. An SEM also has higher magnification and resolution compared to an optical microscope. The SEM machine utilized is the FEI Quanta 3D which is a dual-beam (SEM/FIB) system with both e-beam mode and ion-beam mode and available at the University of New Mexico (see Figure 9). 


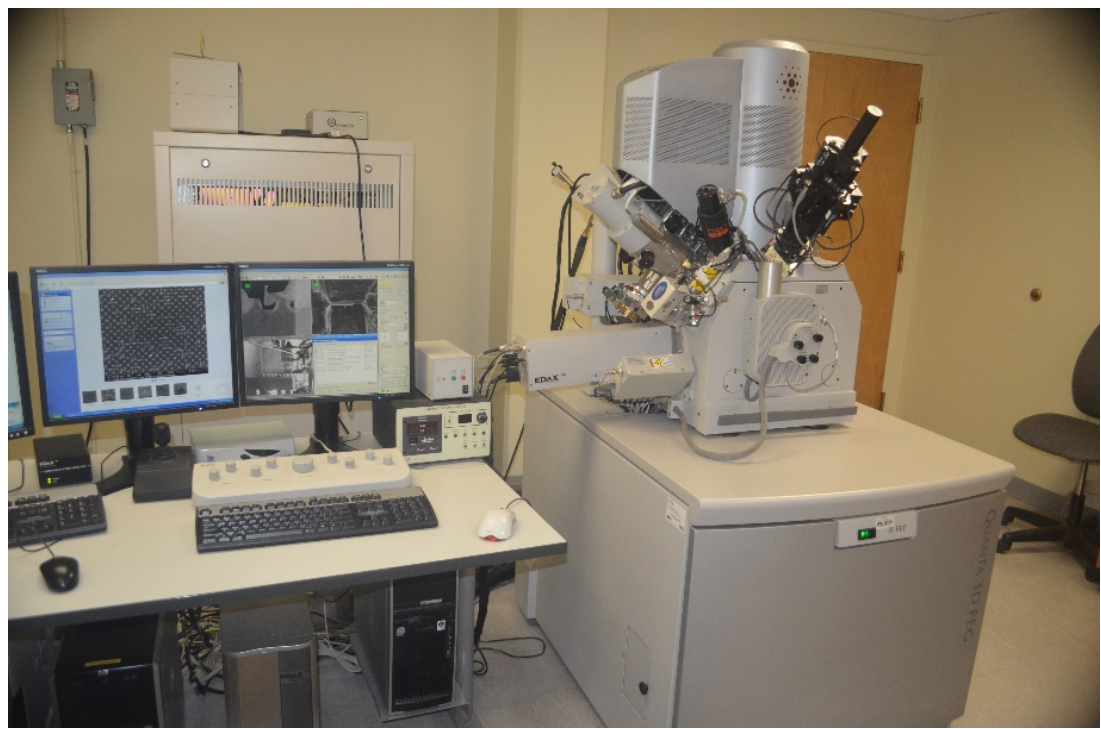

Figure 9. SEM used in the study.

Lastly, Atomic Force Microscopy (AFM) was used in this study to perform nano-scale analysis. The AFM is one kind of SPM (scanning probe microscope) that is designed to measure local properties. These local properties consist of things like height, friction, and magnetism as the probe scratches across the surface of the part. The AFM images where collected using a VEECO DI-3100 atomic force microscope with a MikroMasch atomic tip. The MikroMasch tips are made of an n-type silicon material that has an average tip radius of $8 \mathrm{~nm}$. With having the tip at these atomic sizes, it is possible to pick up the smallest of imperfections on the surface during the AFM analysis. Due to the small dimples in the material, it was decided to use the AFM tapping mode to probe the surface. The tapping mode was set to use a frequency of $270 \mathrm{kHz}$ during the scanning process on a 50 micron by 50 micron grid. The resolution that was used for the different samples ranged from $128 \times 128$ pixel for the smooth sections of the sample to $256 \times 256$ pixels for the rougher section in order to capture all of the roughness.

The images where then processed through a program called WSxM in order to make sure that the images are showing the same color scale. This program also ran a roughness analysis that provided RMS (root mean square) roughness $\left(R_{q}\right)$ and average roughness $\left(R_{a}\right)$ so that we can quantify surface changes due to deformation. In Equations (1) and (2), $Z_{j}$ is the $Z$ displacement at point $j$ and $N$ is the number of points within the scan area. In this program, the images were also converted into 3-D plots of the surface in order to visualize the surface roughness.

$$
\begin{aligned}
& R_{a}=\frac{1}{N} \sum_{j=1}^{N}\left|Z_{j}\right| \\
& R_{q}=\sqrt{\frac{\sum_{j=1}^{N}\left|Z_{j}^{2}\right|}{N}}
\end{aligned}
$$




\section{Results and Conclusions}

Tension testing was initially performed on pristine specimens with no holes. The result for such testing on six samples or specimens is presented in Figure 10. In the figure, the load-displacement curve follows typical shape for structural aluminum. One can clearly see the proportional limit, or point of yielding, and the max tensile force (or max load-bearing force) as well as the displacement-to-failure. It is clear from the figure the specimens give consistent results. Even more specimens that were not polished were tested and gave the same results. Note in the graph the three bottom legends. These were specimens at which the testing stopped at the yield point, max force point and right before total failure. This was done in order to follow the progress of deformation with applied displacement.

One of the first checks performed on these results were in regard to the max tensile force. According to [45], the UTS (max tensile strength) for 6061-T6 aluminum alloy is 45,000 psi. Multiplying this number by the area of the rectangular cross-section of the pristine sample ( 0.5 in $\times 0.25$ in), the max tensile force/load should be $5625 \mathrm{lb}$. According to the load-displacement graphs, the max tensile force is $5400 \mathrm{lb}$, which is very close to the predicted value and is probably off because of the extra surface shaving, i.e. reduced cross-sectional area that resulted from grinding and polishing.

After performing tension tests on the pristine specimens, the specimens with one hole were tested. The load-displacement curves for such specimens are given in Figure 11. Note in the graph the three bottom legends. These were specimens

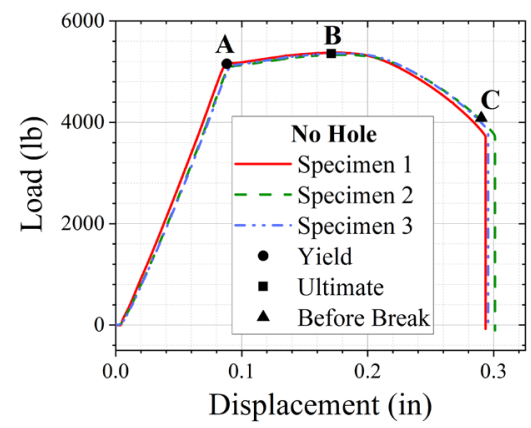

Figure 10. Load vs Displacement curves for specimens with no holes.

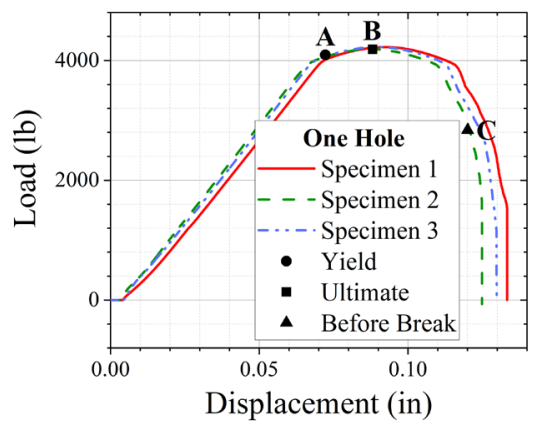

Figure 11. Load vs Displacement for single-hole samples. 
at which the testing stopped at the yield point, max force point and right before total failure. This was done in order to follow the progress of deformation with applied displacement. Here again, the curves seems to follow a similar shape to those in Figure 10 but with clearly reduced max tensile force and displacement-to-failure. This was not surprising given that the hole was predicted to cause stress concentration in the material and hence bring down the load-carrying capacity of the specimen. The weakest section in the specimen is where the hole resides. Hence, using the previous UTS value, and a reduced cross-sectional area equal to $\left((0.5\right.$ in -0.125 in $){ }^{*} 0.25$ in $)$, the max tensile load is expected to be $4218.75 \mathrm{lb}$. Examining Figure 11, the max tensile force is about that number. Figure 12 shows on oblique picture of a deforming one-hole specimen with what appears to be shear banding deformation from it in an X pattern. This is the advantage of the specimen polishing preparation as it allows for clear reveal of the ensuing plastic deformation.

Considering the specimens with two vertical holes, the load-displacement curves are plotted in Figure 13. In it, and comparing to the last two figures, it can be seen that the displacement-to-failure is higher for the two vertical holes than the one-hole specimens! It can also be seen that max tensile load or force is equivalent to the one-hole specimen, i.e. there was no reduction in max load

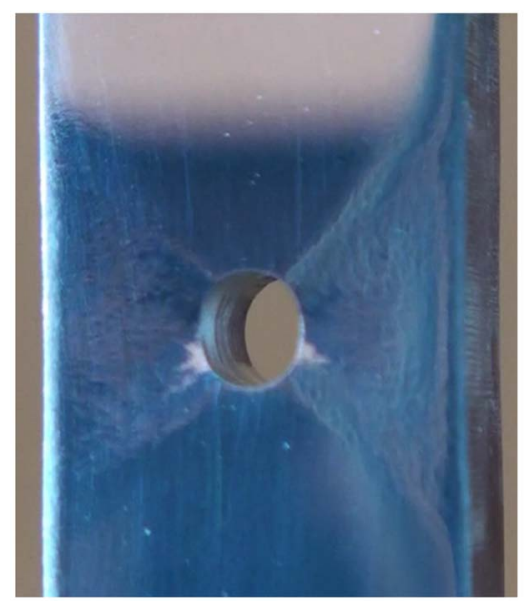

Figure 12. Angled picture of one-hole sample showing shear bands forming in a X pattern.

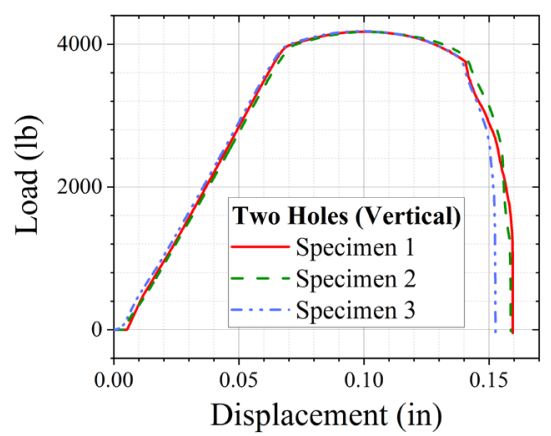

Figure 13. Load vs Displacement curves for samples with two vertically-spaced voids. 
when the number of holes went up by a factor of 2 . In other words, the overall ductility of the specimen increased while not observing a drop in the load-carrying capacity. So despite a doubling of the volume fractions of the voids in the material, the load-carrying capacity was not diminished any and the ductility was actually enhanced! Such concept is not intuitive, as most people would ascertain that increase void volume fraction would lead to a drop in ductility and capacity to carry load. This is thus a welcome outcome for material scientists or mechanical designers although it is not a new concept or findings on its own. Mulholland et al. [43] also reported an increase in ductility with increased number of voids aligned vertically along the tensile axis. However, this prior work dealt with a superplastic metallic material whereas this one deals with a structural metallic material. Hence, it appears that this outcome is present in such vertically-aligned voids along the tensile axis across metallic materials of different ductilities.

This increase in ductility can be explained by the deformation localization being spread over/around two voided areas versus one area in the case of one-hole specimens. Hence instead of one-hole having to compensate plastically for the applied stretch or displacements, two voids/void areas now share in this task and hence deformation is not as severely localized as in the case of one-void.

As for the observed steadiness in the load-carrying capacity, it can be explained in two different ways. First, each void deforms in shear in an X pattern similar to the one hole (Figure 12). See Figure 14. However, these two X patterns interfere with one another, i.e. they cross paths. That means dislocation forest interactions, or at least a significant amount of inelastic dislocation interactions, occurring. Such interactions are known to cause material hardening, similar to the hardening stages in creep, and thus the load-carrying capacity does not suffer in this situation.

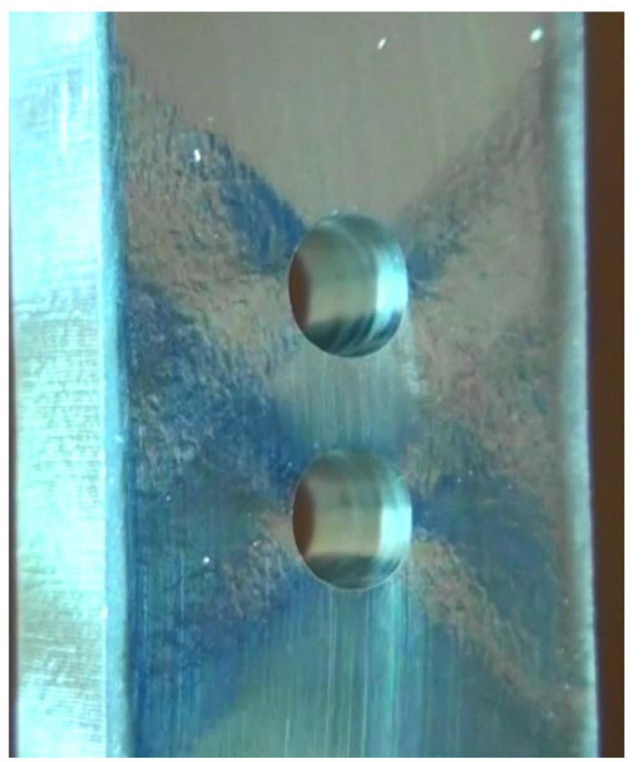

Figure 14. Double Shear-banding picture for each of two vertical voids. 
Another or second explanation here is that the vertical arrangement of the holes actually decreases the stress concentration factor, $K_{t}$ from the typical factor of 3 for a single hole (Figure 15) to a factor less than 3 for two vertical holes (Figure 16). The derivation of the stress concentration factor along the mid cross-section of a void is detailed in the Appendix. It is clear from Figure 16 that the presence of a second hole on top of the first (bottom) one brings down the $K_{t}$ value to the left and right of the hole.

Now, let's consider the case of two horizontal holes. The stress-strain diagrams for such hole configuration is given in Figure 17. From this figure, it can be seen that the displacement-to-failure is less than all previous cases, i.e. it has the lowest ductility. Also, max tensile load or force is also the lowest of all cases. To interpret the drop in the load-carrying capacity we calculate the max load by multiplying the UTS by the reduced cross-sectional area of $((0.5$ in $-2 * 0.125$ in) $* 0.25 \mathrm{in}$ ) which gives a value of $2812.5 \mathrm{lb}$. This value is the least max load value of all cases and it matches the max load values in Figure 17. Another reason for the drop in the max load value for this hole configuration besides the reduction in the cross-sectional area is due to an elevated value of $K_{t}$ as the two neighboring holes actually help elevates one another's stress concentration factor $K_{t}$. Based on the Appendix, the $K_{t}$ for such configuration is shown in Figure 18

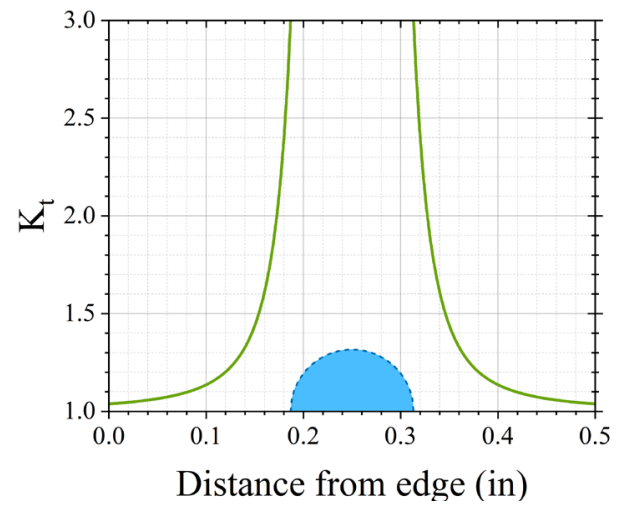

Figure 15. Stress concentration factor for $\sigma_{11}$ for the line directly to the right and left of the hole.

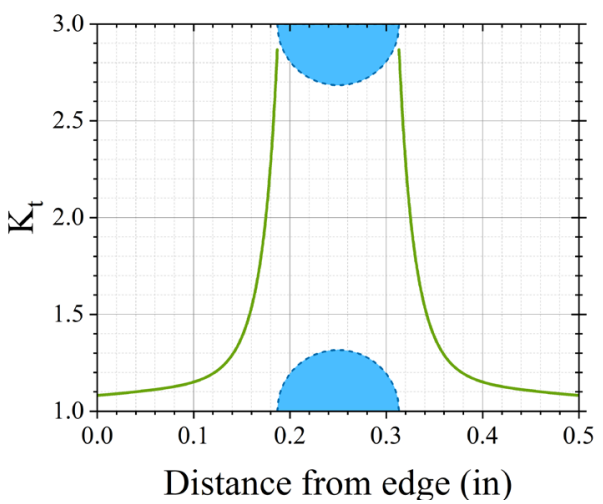

Figure 16. Stress concentration factor for $\sigma_{11}$ for the line directly to the right and left of the bottom hole. 


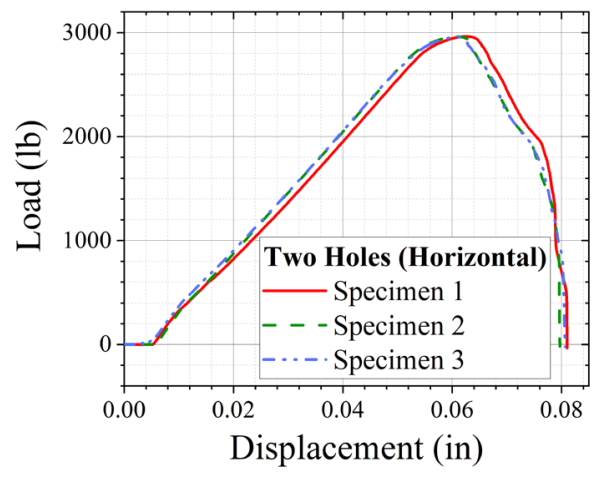

Figure 17. Load vs displacement for two horizontally-spaced voids.

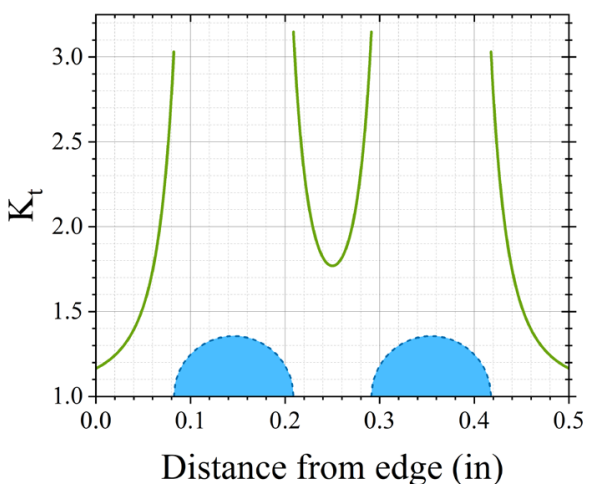

Figure 18. Stress concentration factor for $\sigma_{11}$ direction. The $\mathrm{x}$ axis is starting at the left edge of the sample. The orange line is the factor to the left of the holes, yellow being the stress concentration factor between the holes, and the blue is the factor to the right of both holes.

where $K_{t}$ is slightly greater than for the on-hole situation. Moreover, based on the Appendix work, $K_{t}$ actually increases with decreased spacing between the two equally-sized voids.

Hence again, it is clear that the void volume fraction is not by itself a major determinant of the internal stresses or the mechanical behavior of voided materials. Specimens with two equally-sized voids had significantly differing ductility and load-carrying-capacity if the voids were axial or lateral (perpendicular) to the tensile axis. Again, this is not in-line with conventional continuum mechanics theory heavily relying on the void volume fraction in its formulations.

If during applied displacement the deformed void(s) area is normalized by the initial area then one can plot that against displacement as shown in Figure 19. The figure shows the experimental data and the curve fitted data which shows an exponential growth model for the voids. The exponent for the curves shows the rate of growth of the area. Taking the one-hold model as the comparison basis, one can see that the vertical holes are growing slower. This is due to their interaction that was commented on above. One can also see that the horizontal voids grow the fastest and that is also due to the above commented on reasons. Such exponential growth curve shape has been reported for hole growth in a superplastic material [15] and by [26] but not in structural metals which is the focus 
of this work. Hence in monitoring void growth in structural metals, the failure that comes with horizontal holes (situated perpendicular to the loading axis) would happen sooner than a single hole or two vertical holes.

With respect to SEM imaging, pictures were taken at different spots around a deforming void. For example, if one looks at the bottom of the hole, there is no clear dislocation activity impinging on the surface. Figure 20 shows just that. This corroborates figures like 12 and 14.

However, if SEM images are taken of the bottom right, we expect to see evidence of plastic deformation by dislocation activity. Figure 21 shows just that. The wavy lines are slip bands by dislocations.

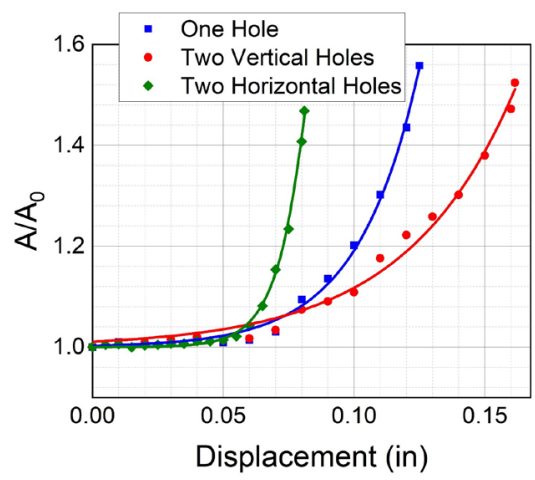

Figure 19. Normalized area vs Displacement for all three hole configurations along with an exponential curve fit for each of the configurations. The fit equation for one hole is $\frac{A}{A_{o}}=2.745 e^{-3} \times \exp (42.47 x)+1$. The fit equation for two vertical holes is $\frac{A}{A_{o}}=0.01076 \times \exp (23.91 x)+1$. The fit equation for two horizontal holes is $\frac{A}{A_{o}}=7.242 e^{-5} \times \exp (108.1 x)+1$.

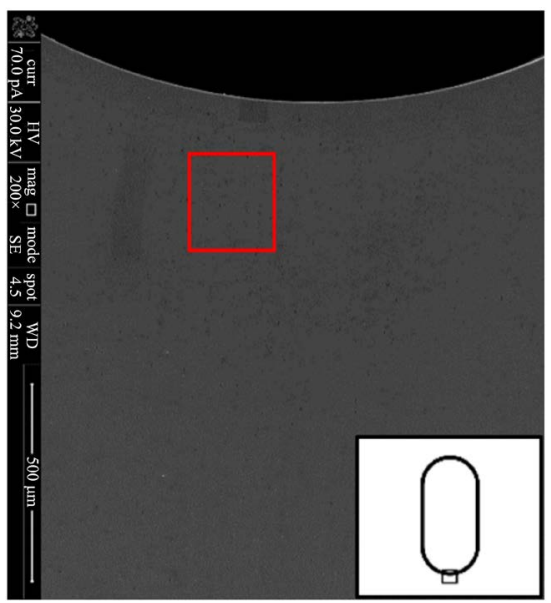

(a)

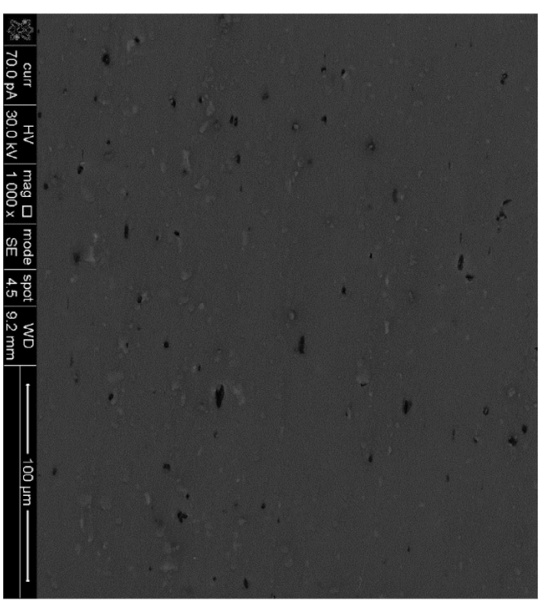

(b)

Figure 20. (a) SEM picture of the bottom of the sample after being pulled to just before failure. This is for a specimen pulled till point $C$ in Figure 11; (b) Zoomed area of the red box in (a) at $1000 \times$ magnification. 


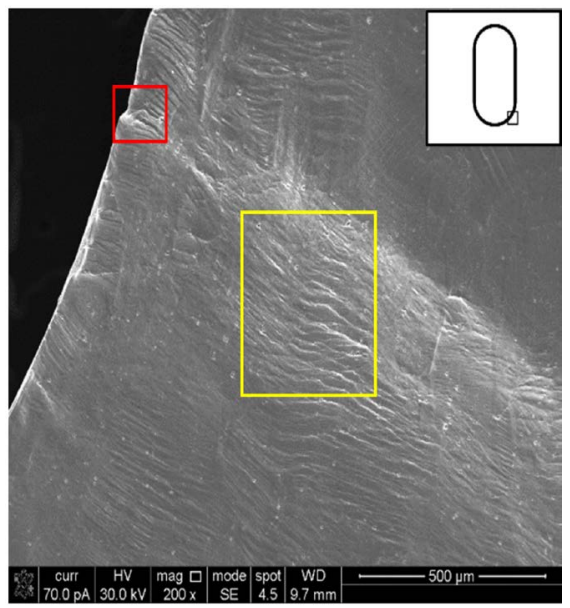

(a)

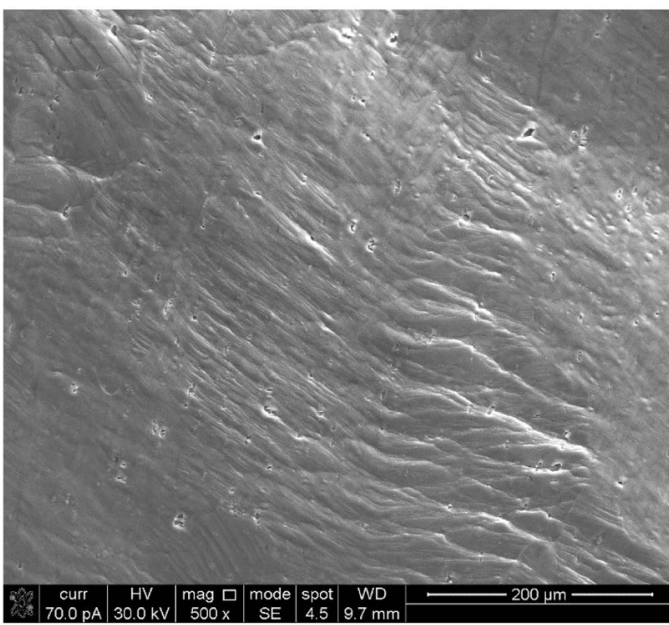

(c)

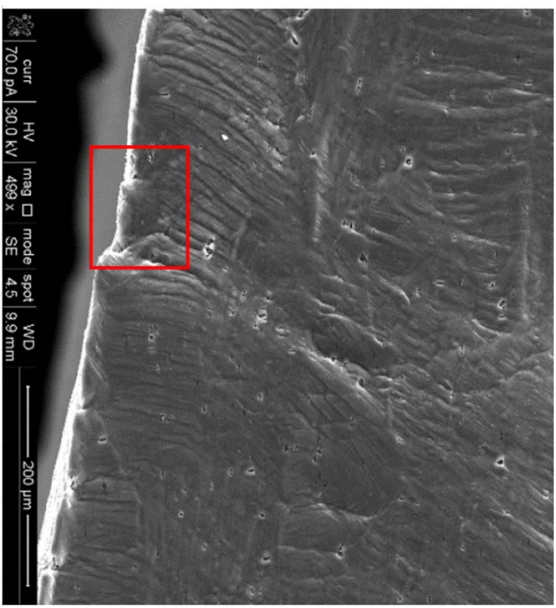

(b)

Figure 21. (a) Bottom right corner at 200x; (b) Zoomed in SEM image of the red box in (a) at 500× magnification; (c) Zoomed in SEM image of the yellow box in (a) at 500× magnification.

Getting another view of this area that is slightly above the previous one, see Figure 22, one can see that there is tearing happening on the surface of the void and even cavitation spots in different locations.

If one examines, the top right of the hole, one can see similar results to the bottom right in the sense of tearing of the edge of the hole, i.e. cracking in a ductile material, and micro cavitation in the material in different spots. See Figure 23. The top, bottom left and top left of the void show similar figures to Figures 20-23 and hence are not shown here for brevity.

Finally for the SEM imaging, the specimen was tilted in order to snap pictures inside the hole. This was done in Figure 24. In the figure, it is observed that a large macro crack has formed prior to total failure. The crack tip was zoomed in on and that shows a lot of micro voids in the material. Also, although the hole surface was not polished like the flat surface, it still shows similar dislocation slip activity or slip bands. 


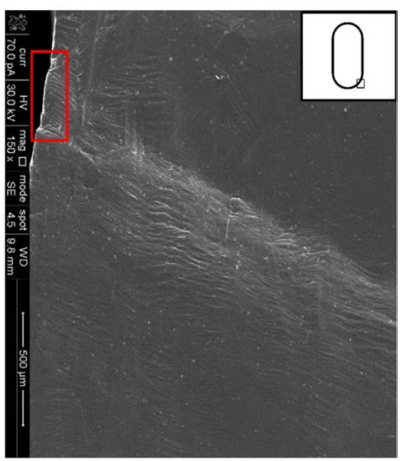

(a)

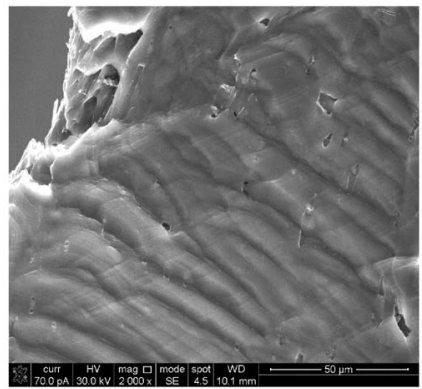

(c)

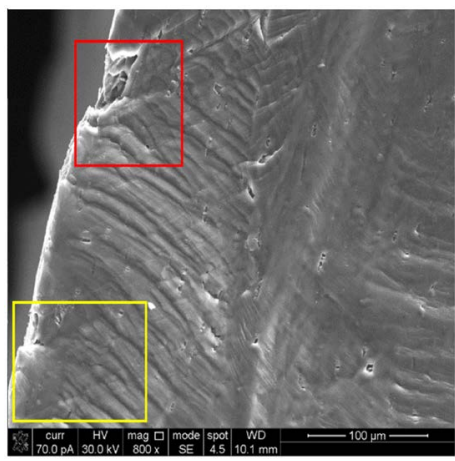

(b)

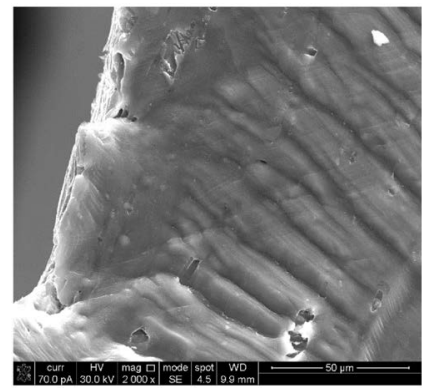

(d)

Figure 22. (a) Bottom right corner at 150× magnification; (b) Zoomed in SEM picture of the red box in (a); (c) Zoomed in SEM picture of the red box in (b); (d) Zoomed in SEM picture of the yellow box in (b).

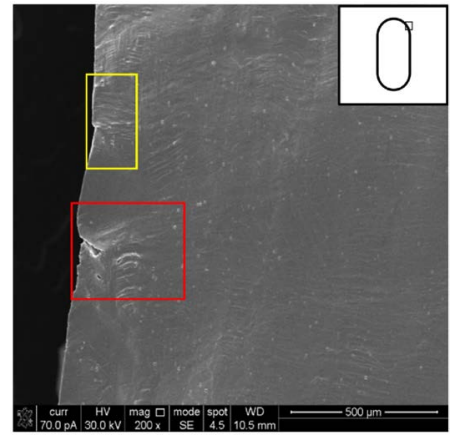

(a)

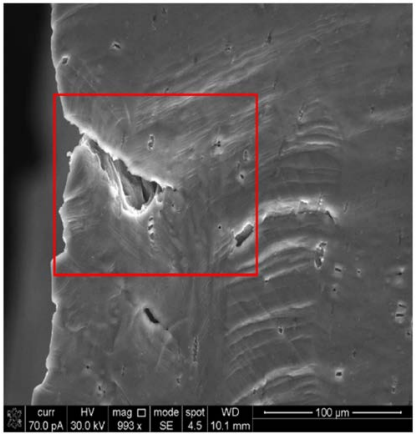

(b)

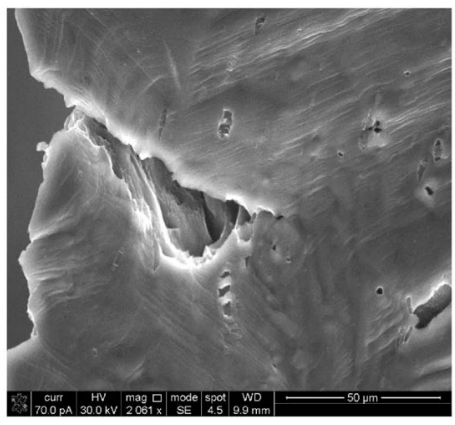

(c)

Figure 23. (a) SEM picture of the upper right side of the sample; (b) Zoomed in SEM picture of the red box in (a) at 1000× magnification; (c) Zoomed in SEM picture of the red box in (b) at $2000 \times$ magnification. 


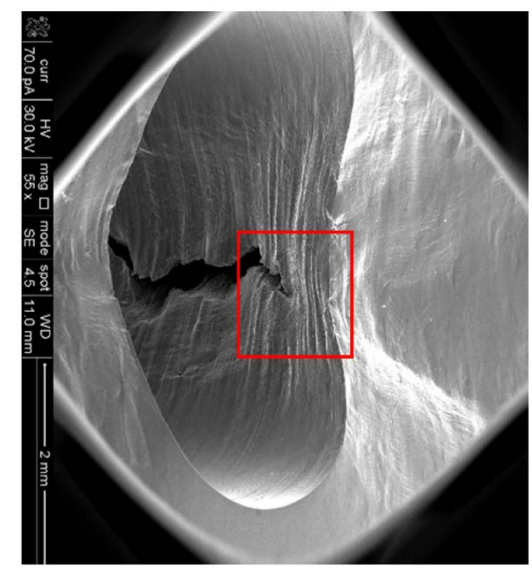

(a)

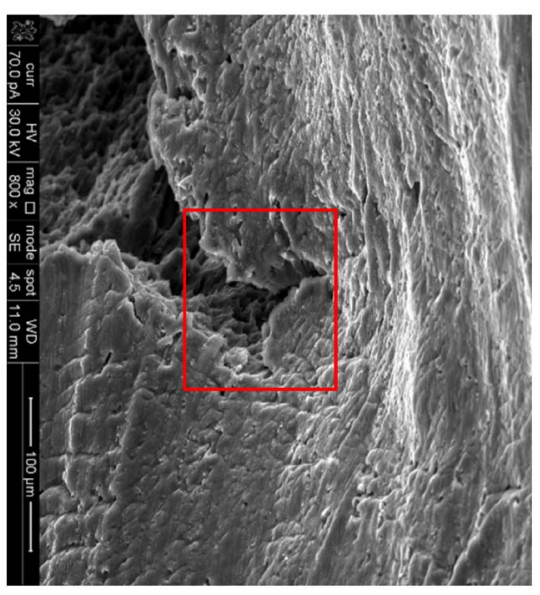

(c)

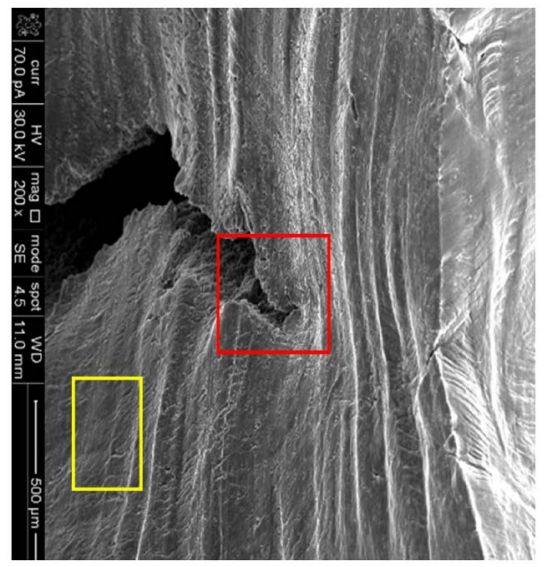

(b)

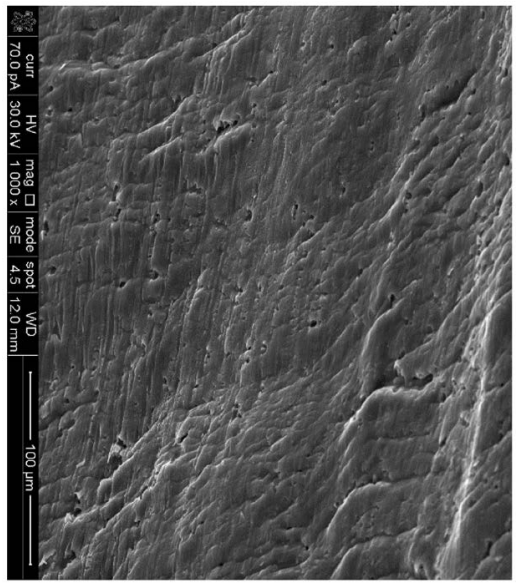

(d)

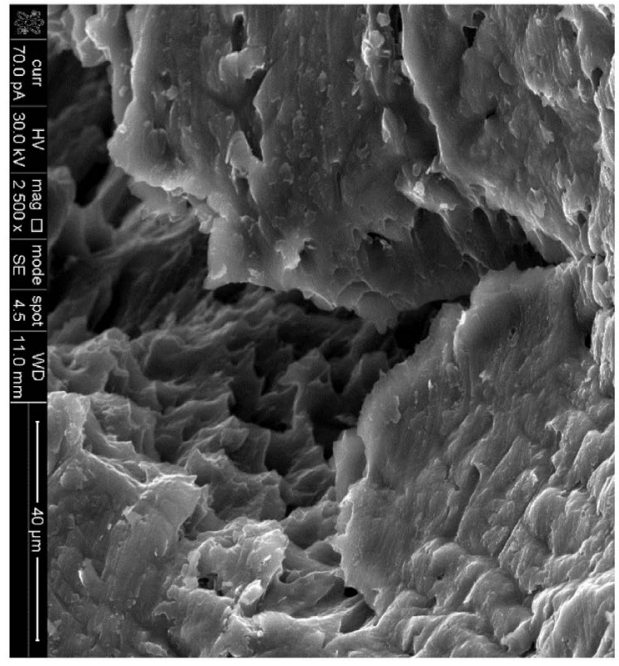

(e)

Figure 24. (a) SEM picture of the inside surface on the inside of the hole at $55 \times$ magnificaiton. The black corners of the picture are just how the images show up at low magnification; (b) Zoomed in picture of the red box shown in (a) at 200× magnification; (c) Zoomed in SEM picture of the red box in (b) at $800 \times$ magnification; (d) Zoomed in SEM picture of the yellow box in (b) at $800 \times$ magnification. (e) Zoomed in SEM picture of the red box in (c) at $2500 \times$ magnification. 
As with respect to the AFM measurements, first a polished specimen was scanned for surface roughness. This formed a basis for comparison with the deformed surface roughness. Figure 25 and Figure 26 show the polished surface. Its surface roughness is also given in Table 1. Figure 27 and Figure 28 shows the deformed specimen at one location near the hole. It is clear from the roughness values (Table 2) that the dislocation slip has increased the roughness of the surface by more than a factor of 2 at this spot. Although AFM can quantify the surface roughness, it is very hard to correlate AFM scans with a particular spot observed in the SEM imaging. An in-situ testing of a sample followed by immediate surface roughness measurements might be doable to do such correlation. That is why although more AFM scans were performed, it was hard to pin point a specific location of the scan with respect to the hole.

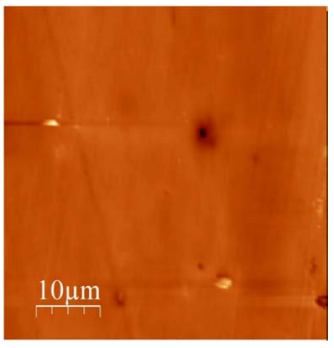

Figure 25. AFM picture of the smooth polished section under the hole for the sample pulled till just before breaking.

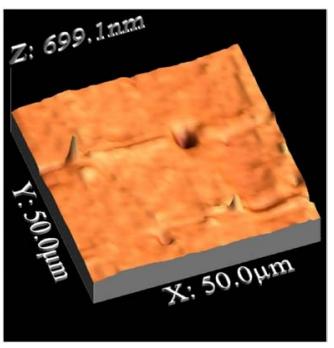

Figure 26. 3D image of the surface shown in Figure 25.

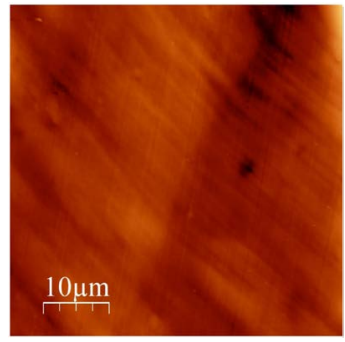

Figure 27. AFM picture of the area about 200 microns below and to the right of hole for the sample pulled till just before breaking.

Table 1. RMS and average roughness for the AFM scanning in Figure 25 and Figure 26.

\begin{tabular}{ccc}
\hline Table 1 & RMS roughness & Roughness average \\
\hline Figure 25 and Figure 26 & 21.5122 & 14.1755 \\
\hline
\end{tabular}




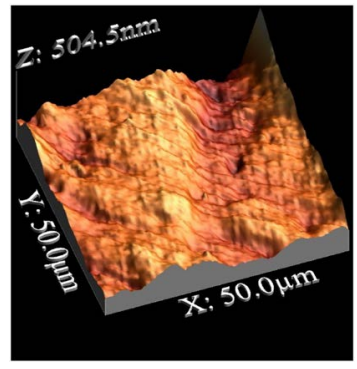

Figure 28. 3D image of the surface shown in Figure 27.

Table 2. RMS and average roughness for the AFM scanning in Figure 27 and Figure 28.

\begin{tabular}{ccc}
\hline Table 2 & RMS roughness & Roughness average \\
\hline Figure 27 and Figure 28 & 48.0123 & 37.4478 \\
\hline
\end{tabular}

\section{Conclusions}

There were several things learned from this study. First, specimen polishing is a good method to observe ensuing plastic deformation of the specimen. Void growth and interaction in structural aluminum alloys is similar to that in superplastic materials, e.g. following an exponential curve or model for growth. Specifically, two vertical voids would slow the growth down (resulting into more specimen ductility) while two horizontal ones to the tensile axis would speed the growth (resulting into less specimen ductility) compared to a one hole model pulled along a line passing through its center. In addition, volume fraction is not a whole encompassing parameter to use to predict void growth under applied loading. Also learned was that the slowed growth for the vertical voids was due to work or strain hardening from the two voids acting against one another. Aided by this was also a reduction in $K_{t}$, the stress concentration factor, for this hole configuration. In the case of the horizontal holes, $K_{t}$ was actually pumped up due to the hole configuration compared to the one-hole model. SEM imaging can be done at different displacement or applied strain points to view the evolution of plasticity with loading. The SEM showed that the main failure occurs due to the formation of macro cracks, mode I cracks, although micro cavitation and significant slip activity precedes that. Finally, AFM scans can provide a quantitative measure of the deformation in the grains captured by SEM imaging. However, it is better if the imaging and scanning can be done in-situ and in the same spots.

\section{Acknowledgements}

The authors would like to acknowledge the contribution of Dr. Ezra Bussmann to the AFM work. This AFM work was performed, in part, at the Center for Integrated Nanotechnologies, an Office of Science User Facility operated for the U.S. Department of Energy (DOE) Office of Science by Los Alamos National Laboratory (Contract 89233218CNA000001) and Sandia National Laboratories (Contract DE-NA-0003525). 


\section{Conflicts of Interest}

The authors declare no conflicts of interest regarding the publication of this paper.

\section{References}

[1] Rice, J.R. and Tracey, D.M. (1969) On the Ductile Enlargement of Voids in Triaxial Stress Fields. Journal of the Mechanics and Physics of Solids, 17, 201-217. https://doi.org/10.1016/0022-5096(69)90033-7

[2] Gurson, A.L. (1977) Continuum Theory of Ductile Rupture by Void Nucleation and Growth: Part 1-Yield Criteria and Flow Rules for Porous Ductile Media. Journal of Engineering Materials and Technology, 99, 2-15. https://doi.org/10.1115/1.3443401

[3] Pilling, J. and Ridley, N. (1988) Cavitation in Superplastic Alloys and the Effect of Hydrostatic Pressure. Res Mechanica, 23, 31-63.

[4] Tvergaard, V. (1990) Material Failure by Void Growth to Coalescence. Advances in Applied Mechanics, 27, 83-151. https://doi.org/10.1016/S0065-2156(08)70195-9

[5] McMeeking, R.M. and Hom, C.L. (1990) Finite-Element Analysis of Void Growth in Elastic-Plastic Materials. International Journal of Fracture, 42, 1-19. https://doi.org/10.1007/BF00018610

[6] Magnusen, P.E., Srolovitz, D.J. and Koss, D.A. (1990) A Simulation of Void Linking during Ductile Micro Void Fracture. Acta Metallurgica et Materialia, 38, 1013-1022. https://doi.org/10.1016/0956-7151(90)90173-E

[7] Eftis, J. and Nemes, J.A. (1991) Evolution Equation for the Void Volume Growth Rate in a Viscoplastic-Damage Constitutive Model. International Journal of Plasticity, 7, 275-293. https://doi.org/10.1016/0749-6419(91)90036-X

[8] Huang, Y. (1991) Accurate Dilatation Rate for Spherical Voids in Triaxial Stress Fields. Journal of Applied Mechanics, 58, 1084-1086.

https://doi.org/10.1115/1.2897686

[9] Barton, D.C., Waheed, M., Mirza, M.S. and Church, P. (1995) A Numerical Study of Ductile Void Growth under Dynamic Loading Conditions. International Journal of Fracture, 73, 325-343. https://doi.org/10.1007/BF00027273

[10] Briottet, L., Klocker, H. and Montheillet, F. (1996) Damage in a Viscoplastic Material-Part I: Cavity Growth. International Journal of Plasticity, 12, 481-505. https://doi.org/10.1016/S0749-6419(96)00017-4

[11] Briottet, L., Klocker, H. and Montheillet, F. (1998) Damage in a Viscoplastic Material-Part II: Overall Behaviour. International Journal of Plasticity, 14, 453-471. https://doi.org/10.1016/S0749-6419(98)00012-6

[12] Nicolaou, P.D., Semiatin, S.L. and Ghosh, A.K. (1999) An Analysis of the Effect of Cavity Nucleation Rate and Cavity Coalescence on the Tensile Behavior of Superplastic Materials. Metallurgical and Materials Transactions A, 31, 1425-1434. https://doi.org/10.1007/s11661-000-0260-6

[13] Horstemeyer, M.F., Lathrop, J., Gokhale, A.M. and Dighe, M. (2000) Modeling Stress State Dependent Damage Evolution in a Cast Al-Si-Mg Aluminum Alloy. Theoretical and Applied Fracture Mechanics, 33, 31-47.

https://doi.org/10.1016/S0167-8442(99)00049-X

[14] Horstemeyer, M.F., Matalanis, M.M., Seiber, A.M. and Botos, M.L. (2000) Micromechanical Finite Element Calculations of Temperature and Void Configuration Effects on Void Growth and Coalescence. International Journal of Plasticity, 16, 
979-1015. https://doi.org/10.1016/S0749-6419(99)00076-5

[15] Khraishi, T.A., Khaleel, M.A. and Zbib, H.M. (2001) A Parametric-Experimental Study of Void Growth in Superplastic Deformation. International Journal of Plasticity, 17, 297-315. https://doi.org/10.1016/S0749-6419(00)00037-1

[16] Taylor, M.B., Zbib, H.M. and Khaleel, M.A. (2002) Damage and Size Effect during Superplastic Deformation. International Journal of Plasticity, 18, 415-442. https://doi.org/10.1016/S0749-6419(00)00106-6

[17] Liu, B., Qiu, X., Huang, Y., Hwang, K.C., Li, M. and Liu, C. (2003) The Size Effect on Void Growth in Ductile Materials. Journal of Mechanics and Physics of Solids, 51, 1171-1187. https://doi.org/10.1016/S0022-5096(03)00037-1

[18] Liu, B., Huang, Y., Li, M., Hwang, K.C. and Liu, C. (2005) A Study of the Void Size Effect Based on the Taylor Dislocation Model. International Journal of Plasticity, 21, 2107-2122. https://doi.org/10.1016/j.ijplas.2005.03.016

[19] Mulholland, M.M., Ege, E.S., Khraishi, T.A., Horstemeyer, M.F. and Shen, Y.-L. (2003) Cavity Mediated Strain Localization and Overall Ductility in Eutectic Tin-Lead Alloy. Materials Science and Engineering: A, 360, 160-168. https://doi.org/10.1016/S0921-5093(03)00429-5

[20] Chen, B., Huang, Y., Liu, C., Wu, P.D. and MacEwen, S.R. (2004) A Dilatational Plasticity Theory for Viscoplastic Materials. Mechanics of Materials, 36, 679-689. https://doi.org/10.1016/j.mechmat.2002.07.001

[21] Siruguet, K. and Leblond, J.-B. (2004) Effect of Void Locking by Inclusions upon the Plastic Behavior of Porous Ductile Solids-I: Theoretical Modeling and Numerical Study of Void Growth. International Journal of Plasticity, 20, 225-254. https://doi.org/10.1016/S0749-6419(03)00018-4

[22] Tvergaard, V. and Niordson, C. (2004) Nonlocal Plasticity Effects on Interaction of Different Size Voids. International Journal of Plasticity, 20, 107-120. https://doi.org/10.1016/S0749-6419(03)00036-6

[23] Zhenhuan, L. and Minsheng, H. (2005) Combined Effects of Void Shape and Void Size-Oblate Spheroidal Micro Void Embedded in Infinite Non-Linear Solid. International Journal of Plasticity, 21, 625-650. https://doi.org/10.1016/j.ijplas.2004.05.006

[24] Wen, J., Huang, Y., Hwang, K.C., Liu, C. and Li, M. (2005) The Modified Gurson Model Accounting for the Void Size Effect. International Journal of Plasticity, 21, 381-395. https://doi.org/10.1016/j.ijplas.2004.01.004

[25] Jing, P., Khraishi, T., Young, J.A. and Wirth, B.D. (2005) Multi-Scale Simulations of the Effects of Irradiation-Induced Voids and Helium Bubbles on the Mechanical Properties of Aluminum. Philosophical Magazine, 85, 757-767. https://doi.org/10.1080/14786430412331319958

[26] Lecarme, L., Tekoğlu, C. and Pardoen, T. (2011) Void Growth and Coalescence in Ductile Solids with Stage III and State IV Strain Hardening. International Journal of Plasticity, 27, 1203-1223. https://doi.org/10.1016/j.ijplas.2011.01.004

[27] Fritzen, F., Forest, S., Böhlke, T., Kondo, D. and Kanit, T. (2012) Computational Homogenization of Elasto-Plastic Porous Metals. International Journal of Plasticity, 29, 102-119. https://doi.org/10.1016/j.ijplas.2011.08.005

[28] Komori, K. (2014) Evaluation of Ductile Fracture in Sheet Metal Forming Using the Ellipsoidal Void Model. Mechanics of Materials, 77, 67-79. https://doi.org/10.1016/j.mechmat.2014.07.002

[29] Feng, C. and Cui, Z. (2015) A 3-D Model for Void Evolution in Viscous Materials 
under Large Compressive Deformation. International Journal of Plasticity, 74, 192212. https://doi.org/10.1016/j.ijplas.2015.06.012

[30] Xu, S., Su, Y., Chen, D. and Li, L. (2017) Plastic Deformation of Cu Single Crystals Containing an Elliptic Cylindrical Void. Materials Letters, 193, 283-287. https://doi.org/10.1016/j.matlet.2017.02.005

[31] Asim, U., Siddiq, M.A. and Demiral, M. (2017) Void Growth in High Strength Aluminum Alloy Single Crystals: A CPFEM Based Study. Modelling and Simulation in Materials Science and Engineering, 25, 035010. https://doi.org/10.1088/1361-651X/aa5bcc

[32] Siddique, A.B. and Khraishi, T. (2020) A Dislocation near a Cylindrical Hole: A Numerical Treatment. In: Khraishi, T., Ed., Proceedings of the 2020 ASEE GulfSouthwest Annual Conference, Virtual Conference, University of New Mexico, Albuquerque. https://peer.asee.org/35939

[33] Wang, X. and Dong, X. (2020) A Void Evolution Model Accounting for Stress Triaxiality, Lode Parameter and Effective Strain for Hot Metal Forming. International Journal of Mechanical Sciences, 168, 105309. https://doi.org/10.1016/j.ijmecsci.2019.105309

[34] Jiang, X., Earthman, J.C. and Mohamed, F.A. (1994) Cavitation and Cavity-Induced Fracture during Superplastic Deformation. Journal of Materials Science, 29, 54995514. https://doi.org/10.1007/BF00349941

[35] Friedman, P.A. and Gosh, A.K. (1996) Microstructural Evolution and Superplastic Deformation Behavior of Fine Grain 5083Al. Metallurgical and Materials Transactions A, 27, 3827-3839. https://doi.org/10.1007/BF02595632

[36] Weertman, J.R. (1982) Studies of Deformation Induced Grain-Boundary Cavitation. Journal of Metals, 35, A85.

[37] Tait, R.A. and Taplin, D.M.R. (1979) Interaction Effects during the Growth of Holes in a Superplastically Deforming Medium. Scripta Metallurgica, 13, 77-82. https://doi.org/10.1016/0036-9748(79)90394-6

[38] Forero, L.E. and Koss, D.A. (1994) On the Strain-Induced Growth of Neighboring Voids. Scripta Metallurgical et Materialia, 31, 419-422. https://doi.org/10.1016/0956-716X(94)90011-6

[39] Chokshi, A.H. and Langdon, T.G. (1996) A Model Study of Cavity Growth in Superplasticity Using Single Premachined Holes. Metallurgical and Materials Transactions $A$, 27, 2532-2539. https://doi.org/10.1007/BF02652347

[40] Carrino, L., Giuliano, G. and Napolitano, G. (2003) A Study of Premachined Hole Growth in Superplastic Materials. Materials and Design, 24, 137-142. https://doi.org/10.1016/S0261-3069(02)00103-6

[41] Magnusen, P.E., Dubensky, E.M. and Koss, D.A. (1988) The Effect of Void Arrays on Void Linking during Ductile Fracture. Acta Metallurgica, 36, 1503-1509. https://doi.org/10.1016/0001-6160(88)90217-9

[42] Kannan, K. and Hamilton, C.H. (1997) Cavity Distribution Effects on Superplastic Ductility of a Eutectic Pb-Sn Alloy. Scripta Materialia, 37, 455-462. https://doi.org/10.1016/S1359-6462(97)00108-5

[43] Mulholland, M., Khraishi, T., Shen, Y.-L. and Horstemeyer, M. (2006) Void Growth and Interaction Experiments: Implications to the Optimal Straining Rate in Superplastic Forming. International Journal of Plasticity, 22, 1728-1744. https://doi.org/10.1016/j.ijplas.2006.02.004

[44] Takahashi, Y., Yoshitake, H., Nakamichi, R., Wada, T., Takuma, M., Shikama, T. 
and Noguchi, H. (2014) Fatigue Limit Investigation of 6061-T6 Aluminum Alloy in Giga-Cycle Regime. Materials Science and Engineering: A, 614, 243-249. https://doi.org/10.1016/j.msea.2014.07.039

[45] Kalpakjian, S. and Schmid. S. (2014) Manufacturing Engineering \& Technology. 7th Edition, Pearson Publishing Company, Upper Saddle River, New Jersey.

[46] Khraishi, T.A. and Shen, Y.-L. (2012) Introductory Continuum Mechanics with Applications to Elasticity (Revised Edition). Cognella, San Diego. 


\section{Appendix A}

\section{1) Stress distributions around a single hole}

When looking into how a void grows, it is important to understand how the stress is being concentrated around the void. The equations below represent how the stresses around the hole, affected by its presence, behave. The last equation is for the stress concentration factor. The variables in these equations are shown in Figure A1. These equations are based on having two assumptions, one of these assumptions is that the deformation is small, i.e. elastic, while the other is that the hole is in a plate with an infinite width. Because we cannot have a plate with an infinite width these equations will not give an exact value, but it can give a good approximation. These equations are taken from [46].

$$
\begin{gathered}
\sigma_{r r}=\frac{S}{2}\left(1-\frac{R^{2}}{r^{2}}\right)+\frac{S}{2}\left(1+\frac{3 R^{4}}{r^{4}}-\frac{4 R^{2}}{r^{2}}\right) \cos (2 \theta) \\
\sigma_{\theta \theta}=\frac{S}{2}\left(1+\frac{R^{2}}{r^{2}}\right)-\frac{S}{2}\left(1+\frac{3 R^{4}}{r^{4}}\right) \cos (2 \theta) \\
\sigma_{r \theta}=-\frac{S}{2}\left(1-\frac{3 R^{4}}{r^{4}}+\frac{2 R^{2}}{r^{2}}\right) \sin (2 \theta) \\
K_{t}=\frac{\sigma_{11}}{S}
\end{gathered}
$$

These equations are needed when investigating how the stress concentration factor changes in the presence of multiple holes in the specimen/sample.

\section{2) Stresses from two vertical holes}

To calculate $K_{t}$ the $\sigma_{11}$ normal stress will be focused on along the dashed line in Figure A2. First, equations relating $r, R, \theta, a$ and $d$ are needed.

$$
\begin{gathered}
\tan \theta=\frac{a}{d}, \cos \theta=\frac{d}{r}, \sin \theta=\frac{a}{r} \\
r=\sqrt{a^{2}+d^{2}}
\end{gathered}
$$

The stress tensor $\sigma^{\prime}$ at any material point along the dashed line with coordinates $(r, \theta)$ due to the remotely applied stress and the top hole (without considering the bottom hole), and the stress tensor $\sigma^{\prime \prime}$ due to the remotely applied stress and the bottom hole (without considering the top hole) can separately be

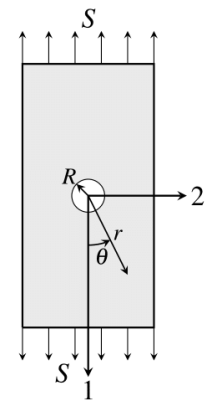

Figure A1. Loading configuration for a one hole specimen/sample. 


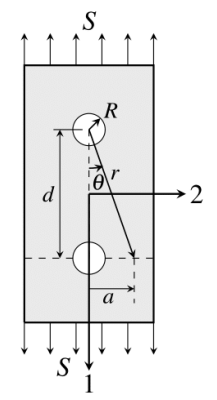

Figure A2. Loading configuration for a sample/specimen with two vertical holes.

found using equations, (i - iii). Now that stress tensors $\sigma^{\prime}$ and $\sigma^{\prime \prime}$ need to be rotated in the correct directions, i.e. transformed, before summing to calculate the total stress tensor in the 12-coordinate system at point $(r, \theta)$ along the dashed line. Finally we subtract from the sum the remotely applied stress $S$ since it would be counted twice with the calculations of $\sigma^{\prime}$ and $\sigma^{\prime \prime}$.

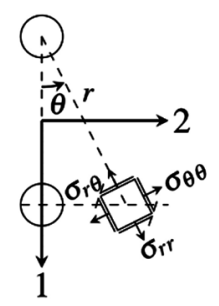

In order to rotate the $r$-direction in the 1-direction and the $\theta$-direction in the 2 -direction, the following rotational transformation matrix $\beta$ is needed:

$$
\left[\begin{array}{ccc}
\cos \theta & \sin \theta & 0 \\
-\sin \theta & \cos \theta & 0 \\
0 & 0 & 1
\end{array}\right]=\boldsymbol{\beta},\left[\begin{array}{ccc}
\cos \theta & -\sin \theta & 0 \\
\sin \theta & \cos \theta & 0 \\
0 & 0 & 1
\end{array}\right]=\boldsymbol{\beta}^{\mathrm{T}}, \quad \boldsymbol{\beta} \boldsymbol{\beta}^{\mathrm{T}}=\left[\begin{array}{lll}
1 & 0 & 0 \\
0 & 1 & 0 \\
0 & 0 & 1
\end{array}\right]
$$

This $\beta$ will then be multiplied by the stress matrix expressed in the polar coordinate system in order to obtain the stress tensor in 12-coordinate system:

$$
\boldsymbol{\sigma}=\boldsymbol{\beta}_{1}^{\mathrm{T}} \boldsymbol{\sigma}^{\prime} \boldsymbol{\beta}_{1}+\boldsymbol{\beta}_{2}^{\mathrm{T}} \boldsymbol{\sigma}^{\prime \prime} \boldsymbol{\beta}_{2}
$$

For the transformation matrix $\boldsymbol{\beta}_{1}$, the angle is $\theta=0$. For the transformation matrix $\boldsymbol{\beta}_{2}$, the transformation angle is $\theta=\frac{\pi}{2}$ (since the field points of interest are all along the dashed line on either side of the bottom hole). Instead of using the matrix form for the stress tensor transformation, i.e. $\boldsymbol{\beta}^{\mathrm{T}} \boldsymbol{\sigma} \boldsymbol{\beta}$, one can alternatively use the indicial notation form:

$$
\sigma_{i j}=\beta_{p i} \beta_{q j} \sigma_{p q}^{\prime}
$$

Using the above equations, one can write:

$$
\sigma_{11}=(\cos \theta)^{2} \sigma_{r r}^{\prime}+(\sin \theta)^{2} \sigma_{\theta \theta}^{\prime}-2 \cos \theta \sin \theta \sigma_{r \theta}^{\prime}+\sigma_{\theta \theta}^{\prime \prime}-S
$$

The following parameters are used for plotting graphs:

$$
d=0.2088 \text { in, } R=0.0632 \text { in }
$$

